\title{
PROBLEMAS DE ENFERMAGEM E SUA CONCEITUAÇÃO
}

\section{Maria Romana Friedlander*}

FRIEDLANDER, M. R. - Problemas de enfermagem e sua conceituação. Rev. Esc. Enf. USP, 11(3): 325-330, 1977.

A autora apresenta algumas definições emitidas pelos autores de "problemas de enfermagem" e tece comentários sobre a utilização dessas definições e suas implicações teóricas. Diferencia "problemas de enfermagem" de "problemas do paciente" $e$ "necessidade do paciente".

A discussão sobre a ciência de enfermagem e as causas que, levam os profissionais a interessarem-se por este assunto vem se estendendo há muitos anos. A verdade é que os enfermeiros devem, urgentemente, delinear seu futuro através de uma escolha definitiva: ou lutam para atingir um alto grau de conhecimento científico e caracterizar seu campo de atuação desenvolvendo-se como profissionais liberais, ou caminham para aprofundar seus conhecimentos nas artes médicas desenvolvendo-se como assistentes médicos ou médicos auxiliares. Entre estas duas opções, não é difícil acreditar que os enfermeiros brasileiros anseiem por realizarem-se dentro da equipe de saúde como profissionais liberais, atuando lado a lado com profissionais de outras áreas e adquirindo o prestígio que já coroa as realizações dos demais profissionais da área da saúde. A legislação brasileira já garante à enfermagem sua condição de profissional liberal. Contudo, no campo de trabalho, nem sempre o enfermeiro encontra condições de desempenhar sua atividade como tal.

* Professor Assistente das disciplinas Introdução à Enfermagem e Fundamentos de Enfermagem I da EEUSP. 
A escolha da primeira opção exige grande profundidade científica, o manuseio seguro de conceitos teóricos e o mais alto nível de raciocínio e discernimento intelectual. Por esse motivo, os líderes da Enfermagem começaram a analisar o conceito de Enfermagem, a atuação dos enfermeiros junto ao ser humano, a sistemática necessária a essa atuação e os instrumentos que deve possuir e manusear. Desses estudos surgiram algumas questões, em sua maioria, ainda sem resposta definitiva e conceituações diversas, e mesmo divergentes, sobre assuntos de base.

Uma das conceituações, fonte de inúmeras polêmicas, é a de "problema de enfermagem". Esta expressão está sendo cada vez mais utilizada, pois a pesquisa, no setor da enfermagem, começa a preocupar-se com o aperfeiçoamento da assistência através de estudos de novas e melhores soluções para os problemas de enfermagem. Faz-se mister, portanto, uma discussão sobre esta conceituação.

ABDELLAH (1957), quando discorre sobre a identificação dos aspectos inaparentes dos "problemas de enfermagem" refere-se à expressão como "aquelas dificuldades físicas e emocionais sentidas pelo paciente". ABDELLAH e col. (1961) completam a definição da primeira referindo-se à expressão "problema de enfermagem" como as "condições gerais apresentadas por qualquer paciente ou família nas quais a enfermagem atua". Ao lado disso utilizam a expressão "problemas específicos de enfermagem" como sinônimo de problema de enfermagem. Enriquecem o tema levantando a questão de se desenvolver uma tipologia dos problemas de enfermagem e dos tratamentos de enfermagem. Sugerem, para isso, uma lista de vinte e um problemas de enfermagem. Ao analisar-se essa lista constata-se, com certa surpresa, que os autores se referem aos problemas de enfermagem também como problemas inerentes ao âmbito da atuação da enfermagem e não somente às condições apresentadas pelos pacientes. Verifica-se, portanto, que ABDELLAH e col. deixam dúvidas na conceituação da expressão "problema de enfermagem".

KOMORITA (1963), referindo-se ao diagnóstico de enfermagem, diz que há uma certa confusão na utilização das expressões "problemas de enfermagem" e "dignóstico de enfermagem" conceituando o primeiro como "fenômenos que requerem o exercício do julgamento e a atuação por parte das enfermeiras". Ao interpretarmos essa definição 
podemos reconhecer uma certa identificação com a idéia de ABDELLAH e col.

Em 1968, HORTA, em sua tese, contribui para esta conceituação ampliando e esclarecendo seu significado. Define problema de enfermagem como "a condição ou situação apresentada pelo paciente, família ou comunidade na qual a enfermeira presta, através de sua assistência, seus cuidados profissionais".

JOHNSON, DAVIS e BILITCH (1970), discutindo o mesmo assunto, apresentam duas expressões distintas: Problemas de enfermagem e problemas do paciente. Definem problemas de enfermagem como "questões que devem ser resolvidas pela enfermagem para solucionarem problemas do paciente". E quanto a problemas do paciente mencionam ser "alterações no balanço das necessidades físicas e psíquicas do paciente". Apesar de utilizarem termos diferentes acreditamos que estas definições representam uma tentativa de interpretar as idéias de Abdellah.

BOWER (1972) analisa vários exemplos de problemas de enfermagem e problemas do paciente e, nessas análises nos dá a entender que considera a primeira expressão como "dificuldades resultantes de necessidades do paciente inadequadamente atendidas e que a enfermagem deve superar".

Apesar de parecer existir alguma confusão na terminologia utilizada pelos diversos autores, podemos encontrar pontos comuns. A maioria aceita a definição de "problema de enfermagem" emitida por ABDELLAH et al, (1961) constituida por dois componentes que a identificam: ser uma condição (ou situação, dificuldade, questão, fenômeno) apresentada por um paciente, famflia ou comunidade; e existir atuação (ou assistência, resolução) da enfermagem.

No que se refere à expressão "problema do paciente" parece-nos haver uma tendência para sua utilização como sendo o primeiro componente da definição de problema de enfermagem, ou seja, condição (ou situação, dificuldade, questão, fenômeno) apresentado pelo paciente, família ou comunidade. independente de existir ou não, atuação de enfermagem. Portanto, pode ter ou não sua solução dentro do âmbito de atuação da enfermagem. 
Nosso conhecimento empírico, fundamentado na experiência diária junto ao paciente, tem-nos mostrado que, na verdade, são raros os verdadeiros problemas de enfermagem. O que existe são problemas do paciente, em geral, tão complexos que sua solução só é possível mediante a atuação de vários profissionais. Não só a marcante especialização dos profissionais, como a variedade de aspectos oferecidos por um só problema, faz-nos acreditar que cada problema do paciente tem apenas alguns aspectos nos quais a enfermeira atua. Nesse caso não o podemos denominar problema de enfermagem.

Também merece consideração a afirmação de KOMORITA (1963), BOWER (1972) e RICHEMONT (1973) que "problemas do paciente" e "necessidades do paciente" têm sido usados como sinônimos. Esclarece RICHEMONT (1973) que aquilo que o enfermeiro identifica são os problemas do paciente surgidos de uma necessidade não atendida ou inadequadamente atendida.

Achamos que a expressão "necessidades do paciente" deva ser compreendida como necessidade do indivíduo (família ou comunidade), ou seja, as necessidades básicas humanas cujo atendimento todos os indivíduos precisam manter dentro de certos limites individuais e em contínuo equilíbrio dinâmico. Quando não existe um atendimento adequado surgem os problemas do paciente. Portanto, os problemas do paciente são sintomas de necessidades não atendidas ou inadequadamente atendidas.

Chamamos a atenção para um aspecto destas definições que não pode deixar de ser lembrado: a necessidade de operacionalização e delimitação do conceito. Se, problemas de enfermagem são condições em que o enfermeiro deve atuar, então ao se apresentar uma situação dever-se-á, em primeiro lugar, determinar se o enfermeiro pode atuar para depois, concluirmos se é problema de enfermagem. E fica a questão: quando o enfermeiro pode atuar e quando não lhe é permitido agir porque avança em campo de outro profissional?

HENDERSON (1969) caminha para uma delimitação quando define função específica da enfermagem como "assistir o indivíduo doente ou sadio na execução daquelas atividades que contribuem para a manutenção da saúde ou sua recuperação (ou alcançar uma morte tranquiila), as quais ele desempenharia sozinho se contasse com a capacidade física, a vontade ou o conhecimento necessários". 
HORTA (1974) contribui para esta delimitação quando especifica o que considera assistir em enfermagem e assinala, de maneira geral, os campos ou áreas onde se desenvolvem as funções da enfermagem.

Esta questão tem sido levantada com frequiência e tem forçado o abandono ou a não aceitação de várias definições surgidas para a enfermagem. O desenvolvimento da profissão através do tempo tem contribuido para aumentar as dúvidas quanto à delimitação de suas funções. As atividades do enfermeiro têm sofrido marcantes ampliações e modificações. São diretamente influenciadas pela estrutura social e, podemos observar que, em cada comunidade, elas se apresentam com aspectos diferentes. Os teóricos, portanto, têm sentido sérias dificuldades em definí-las porque, ou a definição objetiva e operacional não abrange todos os aspectos da profissão, ou a definição é tão generalizada que ultrapassa os setores exclusivos da enfermagem.

Como o assunto é extremamente sério, complexo e difícil sugerimo-lo como tema de discussão, estudos e pesquisas futuras.

Acreditamos que os enfermeiros devem continuar lutando no sentido de universalizar a linguagem empregada para concretizar a efetivação da comunicação e construir uma terminologia própria da enfermagem.

FRIEDLANDER, M. R. - Nursing problems and its conceptuation. Rev. Esc. Enf. USP, 11(3): 325-330, 1977.

The author reviews the literature regarding "nursing problems" and comments on the employment of these concepts and its theoretical entanglement, establishing the difference among "nursing problems", "patient's problems" and "patient's needs". 


\section{REFERENCIAS BIBLIOGRÁFICAS}

ABDELLAH, F. G. Methods of identifying covert aspects of nursing problems. Nurs. Research, june 1957.

BELAND, I. L., MARTIN, A. \& MATHENEY, R. V. Pacient-centered approachs to nursing. New York, Macmillan, 1961.

BOWER, F. L. The process of planning nursing care: a theorical model. Saint Louis, Mosby, 1972.

HENDERSON, V. The nature of nursing. 3. ed. New York, Macmillan, 1969.

HORTA, W. A. A observação sistematizada na identificação de problemas de enfermagem em seus aspectos físicos. Tese de LivreDocência, São Paulo, 1968.

Enfermagem: teoria, conceitos, princípios e processo. Rev. Esc. Enf. USP, 8(1):7-17, mar. 1974.

JOHNSON, N. M., DAVIS, M. L. \& BILITCH, M. J. Problem-solving in nursing practice. Iowa, Brow, 1970.

KOMORITA, N. I. Nursing diagnosis. Amer. J. Nurs., 63(12):83-6, dec. 1963.

RICHEMONT, L. R. Plan de cuidados. Rev. de la Escuela de Enfermeria da Universidad del Zulia, 1(3):14, 1973. 